\title{
EFEITO DE DIFERENTES MATERIAIS NO pH DO SOLO
}

\author{
C.A.C. VELOSO'; A.L. BORGES ${ }^{2}$; A.S. MUNIZ; ; I.A. de J.M. VEIGAS ${ }^{1}$
}

RESUMO: A grande maioria dos solos agricolas brasileiros apresenta alta acidez (pH $\mathrm{H}_{2} \mathrm{O}<5,5$ ) sendo um dos principais responsáveis pela baixa produtividade das culturas. Estes solos exigem a aplicação de corretivos para ejevar o seu pH, neutralizar os efeitos dos elementos toxicos, fornecer $\mathrm{Ca}$ e $\mathrm{Mg}$ como nutrientes e aumentar a produtividade das culturas. Com o objetivo de verificar o efeito de diferentes materiais (calcário calcinado e dolomitico, escória e gesso) no pH do solo, em função da dose aplicada (2, 4 e 6 t/ha) e do tempo de incubaçăo (25, 50 e 75 dias), foi conduzido trabalho em condiç̃es de laboratorio. Apos o perfodo de incubaçăo e determinaçăo do pH em aguá, concluiu-se que: a) todos os materiais, com exeção do gesso, foram eficientes para elevar o pH do solo. b) o efeito corretivo do material foi funcăo do seu poder de neutralizaçáo (PN), ou seja, para uma mesma dose e tempo, quando maior o PN, maior o efeito do material no pH do solo; c) dentre os materiais estudados, o calcário calcinado foi o que provocou o maior aumento de pH, seguido do calcário dolomítico e da escória; d) a maior dose aplicada de cada corretivo correspondeu maior elevação de pH do solo.

Descritores: calcário calcinado, dolomítico, escória, gesso, pH.

\section{EFFBCT OF DIFTERENT MATERIALS ON SOL pH}

ABSTRACT: The great majority of Brazilian agricultural soils presents high acidity $\left(\mathrm{pH} \mathrm{H}_{2} \mathrm{O}<5,5\right.$ ) which is one of the main causes of low crop yields. These soils demand lime materials to increase their pH, to neutralize the toxic element effects, to supply calcium and magnesium as nutrients and to increase crop yields. This laboratory experiment was carried out to evaluate the effect of different materials (calcinated and dolomitic limestone, scoria and gypsum) on soil $\mathrm{pH}$, as affected by the applied dosis $(2,4$ and 6 tons per hectare) and the incubation time (25, 50 and 75 days). It was concluded that: a) all materials, except gypsum, were efficient in increasing the soil pH; b) the lime material effect was related to its neutralization power, i.e., for the same dosis and time, the highest neutralization power had the highest effect on soil pH; c) among the used materials, the calcinated limestone determined the highest increase in soil pH, followed by the dolomitic limestone and scoria; d) the highest dosis for each material corresponded to the highest $\mathrm{pH}$ increase.

Key Words: calcinated limestone, dolomitic, scoria, gypsum, $\mathrm{pH}$.

\section{INTRODUÇÃO}

A acidez do solo refere-se a sua capacidade de liberar prótons, passando de um determinado estado a outro em relação a um de referência (JACKSON, 1963). Os estados podem ser especificados em termos de $\mathrm{pH}$ ou outro índice.

Várias são as causas da acidez do solo. Segundo MALAVOLTA (1985) a água lava as bases do complexo de troca deixando íons $\mathrm{H}^{+}$em seu lugar; com o abaixamento do $\mathrm{pH}^{+}$a valores muito baixos pode ocorrer a decomposição de minerais de argila e ocasionar o apareçimento de Al troćlvel; a oxidação microbiana do $\mathrm{N}$ amoniacal conduz à liberação de íons $\mathrm{H}^{+}$; a raiz "troca" $\mathrm{H}^{+}$por cátions que a planta absorve mantendo o equilíbrio eletrostático; também a matéria orgânica libera íons $\mathrm{H}^{+}$no meio, através da dissociação dos seus grupos carboxilícos e fenólicos.

Os solos agrícolas brasileiros, na maioria, apresentam média a alta acidez $\left(\mathrm{pH} \mathrm{H} \mathrm{H}_{2} \mathrm{O}<5,5\right)$, 0

\footnotetext{
1 Centro de Pesquisa Agroflorestal da Amazónia Oriental-CPATU, BELÉM-PA

2 Centro Nacional de Pesquisa de Mandioca e Fruticultura - EMBRAPACNPMF, Cruz das Almas-BA.

${ }^{3}$ Universidade Estadual de Maringá, MARINGÁ-PR.
} 
que traz como consequência, a baixa produtividade das culturas. Os solos ácidos geralmente apresentam alumínio e manganês em nível tóxicos, além de deficiências de cálcio, magnésio e fósforo.

O cultivo agrícola dos solos ácidos exige a 76aplicação de corretivos, os quais ao elevarem seu pH, neutralizam o efeito dos elementos toxicos e fornecem cálcio e magnésio como nutrientes. Em se tratando de calćrio dolomítico é predominantemente cálcio se o calcário for calcítico. Segundo ALCARDE (1983; 1985) os materiais que podem ser usados na correção da ácidez dos solos são aqueles que comtém como "constituintes neutralizantes" ou "principios ativos", 6́xidos, hidróxidos, carbonatos e silicatos de cálcio e ou de magnésio, tais como; calcário dolomítico, calcário calcinado, óxido de cálcio ou de magnésio, hidróxido de cálcio, hidróxido de magnésio e escórias.

o calcário dolomítico é o mais utilizado devido a sua relativa frequência $e$ abundância $e$ por constituir fonte de $\mathrm{Ca}$ e $\mathrm{Mg}$. O calćrio calcinado tambem pode ser usado como corretivo. Esse $\epsilon$ obtido pela calcinação parcial do calcário, onde nem todos são decompostos, apresentando 6xidos e carbonatos de $\mathrm{Ca}$ e $\mathrm{Mg}$ em sua constituição. Produtos de características e propriedades intermediárias entre o calcário e a cal (ALCARDE, 1983; 1985), como possíveis substitutos do calcário, são diversos subprodutos de indústrias. Dentre esses, as escórias, subprodutos das indústrias do ferro e do aço, cujos componentes neutralizantes são os silicatos de cálcio e magnésio, comportam-se semelhantemente aos calcários (WUTKE \& GARGANTINI, 1962); CAMARGO, (1972) e apresenta escórias com teores relativamente elevados de micronutrientes, podendo, em alguns casos, justificar seu uso como corretivo e fertilizante. $O$ gesso agrícola $\left(\mathrm{CaSO}_{4} \cdot 2 \mathrm{H}_{2} \mathrm{O}\right)$ é um subproduto da obtenção do ácido fosfórico, utilizado na fabricação de superfosfato tríplo e fosfatos de amônio (MAP e DAP). O gesso não corrige a acidez, isto $\epsilon$, não aumenta o $\mathrm{pH}$ do solo. Assim sendo, não substitui o calcário, mas completa o seu efeito, reduzindo a fitotoxicidade do alumínio em profundidade. $O$ gesso aumenta a quantidade de cálcio nas camadas superfíciais (PAOLINELLI et alii, s/d; PAVAN \& BINGHAM, 1982; VITTI \& MALAVOLTA, 1985) quando adequadamente aplicado (ALCARDE, 1988), isto é, o gesso é um fertilizante que leva cálcio e enxofre ao solo.

o comportamento e a eficiência desses materiais no solo dependem de suas características, como a natureza química dos neutralizantes, o poder de neutralização, a solubilidade, a granulometria, etc.
O objetivo do presente trabalho foi avaliar, em condições de laboratório, o efeito do calcário dolomítico, calcário calcinado, escória e gesso, sobre o $\mathrm{pH}$ do solo, em função do período de incubação e das doses aplicadas.

\section{MATERIAL E MÉTODOS}

O ensaio foi conduzido no laboratório do Departamento de Química da ESALQ, no período de 06 de setembro a 20 de novembro de 1990 , empregando-se o método de incubação em vasos durante 75 dias.

Para avaliar o comportamento de diferentes materiais sobre o pH do solo, foi utilizado um solo ácido cujas características químicas se encontram na Tabela 1 .

Testou-se os seguintes materiais: calcário dolomítico (CD), calcário calcinado (CC), gesso (GE) e escória (ES), em três doses $(2,4,6 \mathrm{t} / \mathrm{ha})$ com quatro repetições, além de uma testemunha sem adicionar o material. Perfazendo um total de 52 vasos. As características químicas dos materiais utilizados no ensaio encontram-se na tabela 2.

Após misturar uniformemente o material nas doses correspondentes com $500 \mathrm{~g}$ de solo, colocou-se a mistura em vasos plásticos abertos, adicionando-se 150 $\mathrm{ml}$ de água destilada em cada vaso, correspondendo à $70 \%$ da capacidade de campo do solo. Durante o périodo de incubação a umidade do solo foi mantida, irrigando-se os vasos duas vezes por semana.

Aos 25,50 e 75 dias após o início da incubação, foram retiradas amostras de solo de cada vaso para determinação do $\mathrm{pH}$ em água, mantendo o solo sempre com, aproximadamente, $30 \%$ de umidade.

$O$ delineamento experimental utilizado foi o inteiramento causualizado com 4 repetições, num arranjo fatorial ( $3 \times 4 \times 3)$, sendo os fatores: A) três períodos de incubação $(25,50$ e 75 dias), B) materiais (calcário calcinado, calcário dolomítico, escória e gesso) e C) doses (2, 4 e 6 t/ha), o que correspondeu a $500,1000 \mathrm{e} 1500 \mathrm{mg} / \mathrm{vas}$. Foi incluído um tratamento extra (testemunha) sem aplicação de nenhum material.

Inicialmente foi feita uma análise de variância geral, incluindo o tratamento extra. Em seguida foi efetuada uma análise considerando os fatores em todos os seus níveis. Realizou-se análise de regressão polinomial para os fatores periodo de incubação e doses, sendo que as médias foram comparadas através do teste de Tukey, ao nível de $1 \%$ de probabilidade. 
Tabela 1. Características químicas do solo utilizado no ensaio (1).

\begin{tabular}{|c|c|c|c|c|c|c|c|c|c|c|c|}
\hline $\begin{array}{l}\mathrm{pH}^{(1)} \\
\mathrm{H}_{2} \mathrm{O}\end{array}$ & $\begin{array}{l}\mathrm{pH}^{(3)} \\
\mathrm{CaCl}_{2}\end{array}$ & $\mathbf{C}^{(4)}$ & $P^{(S)}$ & $\mathbf{K}$ & $\mathrm{Ca}^{(\theta)}$ & $\mathbf{M g}^{(\odot)}$ & $\mathbf{A l}^{(\theta)}$ & $\begin{array}{l}\mathrm{H}+ \\
\mathrm{Al}^{(7)}\end{array}$ & SB & CTC & $\mathbf{v}$ \\
\hline (2) & (3) & $\%$ & ppm & & & & $\mathrm{meq} /$ & & & & $\%$ \\
\hline 4,9 & 4,3 & 0,4 & 6 & 0,13 & 0,72 & 0,38 & 0,28 & 3,4 & 1,24 & 4,26 & 29 \\
\hline
\end{tabular}

(1) Analises realizadas no laboratório de fertilizantes e corretivos do Departamento de Química da ESALQ.

(2) $\mathrm{pH}$ em $\mathrm{H}_{2} \mathrm{O}$ proporção solo: agua 1:2,5

(3) $\mathrm{pH} \mathrm{em} \mathrm{CaCl}_{2}$ 0,01M proporção solo: água 1:2,5

(4) Método de Walkley e Black.

(5) Extraído pelo Método da Resina (RAIJ \& QUAGGIO, 1983)

(6) Extraídos com $\mathrm{KCl} \mathrm{N}$.

(7) Determinado a partir do extrato solo: solução SMP, conforme RAIJ \& QUAGGIO (1983).

Tabela 2. Caracaterização química dos materiais utilizados.

\begin{tabular}{|c|c|c|c|c|c|c|c|c|}
\hline \multirow[t]{2}{*}{ Materiais } & \multirow{2}{*}{$\begin{array}{l}\text { Componentes químicos } \\
\text { ou fórmula química }\end{array}$} & \multirow{2}{*}{$\begin{array}{l}\text { PN } \\
\%\end{array}$} & $\mathrm{CaO}$ & $\mathrm{MgO}$ & $\mathbf{K}$ & $\mathbf{P}$ & $\mathbf{S}$ & $\mathrm{Al}$ \\
\hline & & & \multicolumn{6}{|c|}{$\%$} \\
\hline $\begin{array}{l}\text { Calcário } \\
\text { dolomítco (CD) }\end{array}$ & $\mathrm{CaCO}_{3}+\mathrm{MgCO}_{3}$ & 102 & 29,2 & 20,5 & - & - & - & - \\
\hline $\begin{array}{l}\text { Calcário } \\
\text { Calcinado (CC) }\end{array}$ & $\begin{array}{l}\mathrm{CaCO}_{3}, \mathrm{MgCO}_{3}, \mathrm{CaO} \\
\mathrm{MgO}, \mathrm{Ca}(\mathrm{OH})_{2} \\
\mathrm{Mg}(\mathrm{OH})_{2}\end{array}$ & 124 & 42,5 & 30,6 & & & & \\
\hline Gesso (GE) & $\mathrm{CaSO}_{4} \cdot 2 \mathrm{H}_{2} \mathrm{O}$ & - & 29,0 & - & - & - & 16 & \\
\hline Escória (ES) & $\mathrm{CaSiO}_{3}, \mathrm{MgSiO}_{3}$ & 86 & 43,4 & 7,6 & 0,03 & 1,00 & 0,17 & 0,89 \\
\hline
\end{tabular}

(1) Análises realizadas no Laboratório de Fertilizantes e Corretivo do Departamento de Química da ESALQ, segundo metodologia proposta em BRASIL (1983).

\section{RESULTADOS E DISCUSSÃO}

Os dados considerados para as análises estatísticas estão contidos na Tabela 3. A análise estatística geral, levando-se em conta o tratamento extra (testemunha) indicou haver efeito altamente significativo para os tratamentos, o que permitiu a realização de análises de regressão polinimial para estudar os efeitos dos fatores e suas interações.

Observa-se pela Tabela 3 que, aos 25 dias houve elevação do $\mathrm{pH}$ em todos os tratamentos, e que aos 50 e 75 dias, esses valores apresentaram uma pequena redução.

A elevação do $\mathrm{pH}$ aos 25 dias no tratamento testemunha pode ser resultado da liberação de amônia durante a fase inicial de mineralização da matéria orgânica, enquanto sua redução aos 50 dias provavelmente se deva à nitrificação dessa amônia liberada. Para os demais tratamentos, o fato do $\mathrm{pH}$ ter diminuído com o período de incubação, pode ser consequência do aumento da concentraçãa de sais no solo, uma vez que este aumento reduz o $\mathrm{pH}$, o que se deve em parte à ação da dupla camada elétrica, fazendo com que o gradiente de concentração do íon hidrogênio elétrica se reduza e o pH diminua (RAlJ, 1986). A equação de regressão obtida para períodos de incubação foi $y=7,29-0,71 x+0,10 x^{2}$, mostrando um efeito quadrático em consequencia do decréscimo de $\mathrm{pH}$ após os 25 dias, em decorrência do provável efeito da concentração salina. 
Tabela 3 - Valores de pH de amostras de solo tratadas com diferenres doses de calcário calcinado, calcário dolomítico, escória e gesso, durante três períodos de incubação.

\begin{tabular}{||lccccc||}
\hline \multicolumn{1}{|c}{ Materiais } & Dose & \multicolumn{4}{c}{ Período de Incubação (dias) } \\
\cline { 5 - 6 } & t/ha & 0 & 25 & 50 & 75 \\
\hline TESTEMUNHA & 0 & 4,9 & 5,69 & 5,46 & 4,64 \\
CALCÁRIO CALCINADO & 2 & 4,9 & 7,13 & 6,54 & 6,44 \\
Calcário Calcinado & 4 & 4,9 & 7,86 & 7,50 & 7,44 \\
Calcário Calcinado & 6 & 4,9 & 8,19 & 8,13 & 8,18 \\
CALCÁRIO DOLOMíTICO & 2 & 4,9 & 6,49 & 5,71 & 5,66 \\
Calcário Dolomítico & 4 & 4,9 & 7,01 & 6,50 & 6,61 \\
Calcário Dolomítico & 6 & 4,9 & 7,29 & 7,03 & 7,16 \\
ESCóRIA & 2 & 4,9 & 6,21 & 5,75 & 5,38 \\
Escória & 4 & 4,9 & 6,88 & 6,10 & 6,03 \\
Escória & 6 & 4,9 & 7,28 & 6,55 & 6,51 \\
GESSO & 2 & 4,9 & 5,43 & 5,28 & 4,28 \\
Gesso & 4 & 4,9 & 5,30 & 5,24 & 4,67 \\
Gesso & 6 & 4,9 & 5,26 & 5,16 & 4,61 \\
\hline
\end{tabular}

Os resultados da análise da variância para os dados de $\mathrm{pH}$ em relação aos fatores, períodos de incubação, produtos, doses e suas interações, mostraram que todos os fatores apresentaram influência sobre os valores de $\mathrm{pH}$ do solo, com exceção da interação tripla.

Os resultados da comparação das médias pelo teste de Tukey, ao nível de $1 \%$ de significância no final do experimento, mostraram que os valores mais altos de pH $(7,4)$ foram obtidos com a aplicação de calćrío calcinado, vindo a seguir os valores obtidos com o calcário dolomítico com pH $(6,6)$ (Tabela 4). Esses resultados estão de acordo com os valores do poder de neutralização (PN) dos respectivos materiais estudados, visto que o calcário calcinado foi o que apresentou o maior PN, além conter uma base forte, seguido do calcário dolomítico e a escória, os quais contém bases fracas.

A comparação das médias dos valores de $\mathrm{pH}$ em relação à interação produtos versus período de incubação, através do teste de Tukey, ao nível de $1 \%$
Tabela 4 - Efeito geral de diferentes materiais sobre o $\mathrm{pH}$ do solo.

\begin{tabular}{|lc|}
\hline Materiais & Médias (1) \\
\hline Calcário Calcinado & $7,49 \mathrm{a}$ \\
Calcário Dolomítico & $6,61 \mathrm{~b}$ \\
Escória & $6,30 \mathrm{c}$ \\
Gesso & $5,07 \mathrm{~d}$ \\
\hline
\end{tabular}

(1) As médias seguidas por letras distintas diferem estre si ao nível de $1 \%$ de probabilidade pelo Teste de Tukey.

de probabilidade, encontram-se na Tabela 5. Observa-se que após 25 dias de incubação do solo, o calcário calcinado foi o que apresentou maior efeito corretivo proporcionando um $\mathrm{pH}$ de 7,7 , vindo a seguir o calcário dolomítico com pH de 6,9 e a escória com 6,7. 
Esse valor de pH mais elevado no calcário calcinado, se deve ao seu maior poder de neutralização (Tabela 2). Além disso, o calcário calcinado é constituido de 6 xidos (base forte) e carbonatos (base fraca). A base forte dissocia-se completamente liberando rapidamente o radical $\mathrm{OH}$. $O$ gesso não teve efeito sobre $\mathrm{o} \mathrm{pH}$ do solo, como era esperado, uma vez que esse produto não é corretivo da acidez do solo (ALCARDE, 1988).

Tabela 5. Efeito de diferentes materiais no $\mathrm{pH}$ do solo em três períodos de incubação (1).

\begin{tabular}{||lccc|}
\hline Materiais & \multicolumn{4}{c|}{ Período de Incubação (dias) } \\
\cline { 2 - 4 } & 25 & 50 & 75 \\
\hline $\begin{array}{l}\text { Calcário } \\
\text { Calcinado }\end{array}$ & $7,72 \mathrm{a}$ & $7,38 \mathrm{a}$ & $7,35 \mathrm{a}$ \\
$\begin{array}{l}\text { Calcário } \\
\text { Dolomítico }\end{array}$ & $6,92 \mathrm{~b}$ & $6,41 \mathrm{~b}$ & $6,47 \mathrm{~b}$ \\
$\begin{array}{l}\text { Escória } \\
\text { Gesso }\end{array}$ & $6,78 \mathrm{~b}$ & $6,16 \mathrm{c}$ & $5,97 \mathrm{c}$ \\
\hline
\end{tabular}

(1) As médias seguidas por letras distintas diferem entre si ao nível de $1 \%$ de probabilidade pelo teste de Tukey.

O resultados da comparação das médias de pH em relação à interação doses versus produtos, pelo teste de Tukey ao nível de $1 \%$ de significância, encontram-se na Tabela 6 . Observa-se que o mais alto valor de $\mathrm{pH}$ foi de 8.1, obtido com a aplicação de 6 tha de calcário calcinado. Os mais altos valores de $\mathrm{pH}$ obtidos com calcário dolomítico e escória, foram também alcançados com 6 tha, sendo 7,1 e 6,8, respectivamente. As doses de gesso não apresentaram nenhum efeito sobre $\mathrm{o} \mathrm{pH}$ do solo. A equação de regressão obtida para doses $(\mathrm{y}=5,17+0,40 \mathrm{x}$ $0,02 x^{2}$ ), mostrou um efeito quadrático significativo.

Com relação à interação doses versus período de incubação constatou-se que o tratamento 6 , 25 dias após a incubação, propiciou maior aumento do valor de $\mathrm{pH}$ do solo, tendo sido possível alcançar a neutralidade com os materiais calcários. (Tabela 7). Aos 50 e 75 dias após a incubação, os valores mais altos de pH foram também obtidos com $6 \mathrm{t} / \mathrm{ha}$, sendo de 6,7 e 6,6 ,
Tabela 6 . Efeito das doses sobre os valores de pH do solo, em cada material testado (1).

\begin{tabular}{|c|c|c|c|c|}
\hline \multirow{2}{*}{$\begin{array}{l}\text { Dose } \\
\text { (t/ha) }\end{array}$} & \multicolumn{4}{|c|}{ MATERIAIS } \\
\hline & $\begin{array}{l}\text { Dolomí } \\
\text { tico }\end{array}$ & $\begin{array}{l}\text { Calci- } \\
\text { nado }\end{array}$ & Gesso & Escória \\
\hline 2 & $5,95 \mathrm{c}$ & $6,70 \mathrm{c}$ & $5,12 \mathrm{~ns}$ & $5,77 \mathrm{c}$ \\
\hline 4 & $6,70 b$ & $7,60 \mathrm{~b}$ & $5,07 \mathrm{~ns}$ & $6,33 \mathrm{~b}$ \\
\hline 6 & $7,15 \mathrm{a}$ & $8,16 \mathrm{a}$ & $5,01 \mathrm{~ns}$ & $6,81 \mathrm{a}$ \\
\hline
\end{tabular}

(1) As médias seguidas por letras distintas diferem entre si ao nível de $1 \%$ de probabilidade pelo teste de Tukey.

Tabela 7. Efeito das doses sobre os valores de pH do solo, em três períodos de incubação (1).

\begin{tabular}{|cccc|}
\hline \multirow{2}{*}{ Doses } & \multicolumn{4}{c|}{ Período de Incubação (dias) } \\
\cline { 2 - 4 }$(\mathrm{t} / \mathrm{ha})$ & 25 & 50 & 75 \\
\hline 2 & $6,31 \mathrm{c}$ & $5,81 \mathrm{c}$ & $5,53 \mathrm{c}$ \\
4 & $6,76 \mathrm{~b}$ & $6,33 \mathrm{~b}$ & $6,18 \mathrm{~b}$ \\
6 & $7,00 \mathrm{a}$ & $6,74 \mathrm{a}$ & $6,61 \mathrm{a}$ \\
\hline
\end{tabular}

(1) As médias seguidas por letras distintas diferem entre si ao nível de $1 \%$ de probabilidade pelo teste de Tukey.

\section{CONCLUSÕES}

1. Todos os materiais, com exceção do gesso, apresentam efeito corretivo de acidez do solo.

2. O efeito corretivo do material é função da natureza do teor dos "constituintes neutralizantes", бxidos, hidróxidos, carbonatos e silicatos de cálcio ou de magnésio, avaliado pelo Poder de Neutralização (PN). Quanto maior o PN do material, maior sua eficiência em corrigir a acidez do solo, em todas as doses.

3. Dentre os materiais estudados, o calcário calcinado foi o que provocou o maior aumento de $\mathrm{pH}$, seguido de calcário dolomítico e da escória, nas mesmas condições de tempo de incubação. 
4. Quanto maior a dose aplicada do corretivo maior foi a elevação do $\mathrm{pH}$ do solo.

\section{REFERÊNCIAS BIBLIGRÁFICAS}

ALCARDE, J.C. Características de qualidade dos corretivos da acidez do solo. SIMPÓSIO SOBRE ACIDEZ E CALAGEM, XV REUNIÃO BRASILEIRA DE FERTILIDADE DO SOLO. Campinas,SP, 1983, p.10-31.

ALCARDE, J.C. Corretivos da acidez dos solos: características de quantidade, In: SEMINÁRIO SOBRE CORRETIVOS AGRÍCOLAS. Fundação Cargill, Piracicaba, 1985, p. 97-119.

ALCARDE,J.C. Contraditória, confusa e polêmica: é a situação do uso do gesso na agricultura. Piracicaba. POTAFOS, 1988. (Informações Agronômicas, 41).

BRASIL. Análise de corretivos, fertilizantes e inoculantes: Métodos Oficiais. Laboratório Nacional de Referência Vegetal (LANARV), 1983. 104p.

CAMARGO, A.P. Influência da granulometria de três materiais corretivos na neutralização da acidez do solo. Piracicaba,SP. ESALQ/USP. 1972. 59p. Dissertação de Mestrado.

JACKSON, M.L. Aluminum bonding in soils: A unifying principle in soil science. Proceedings Soil Science Society of America, Madison, 27(1): 1-9, 1963.

MALAVOLTA, E. Reação do solo e crescimento das plantas. Em: SEMINÁRIO SOBRE CORRETIVOS AGRÍCOLAS. Campinas, Fundação Cargill, p. 364, 1985.

PAOLINELLI, M.T.; OLIVEIRA, P.M. de; SANTOS, P.R.R.S.; LEANDRO, V.P. \& MORAES, W.V. de. Gesso Agrícola. Petrobrás Fertilizantes S.A. Petrofértil, s/d. 16p. (Informe técnico)

PAVAN, M.A.; BINGHAM, F.T.; Toxicity of aluminum to coffee (Coffea arabica, L.) In: Ultisols and $\mathrm{Oxisols}$ amended with $\mathrm{CaCO}_{3}, \mathrm{MgCO}_{3}$ and $\mathrm{CaSO}_{4} \cdot 2 \mathrm{H}_{2} \mathrm{O}$. Soil Soc. Am. Journal, 46(6): 1201-1207. 1982.
RAIJ, B. Van. Propriedades eletroquímicas de solos.In: SIMPÓSIO AVANÇADO DE QUÍMICA E FERTILIDADE DO SOLO, Campinas-SP, Fundação Cargill, p.9-41, 1986.

RAIJ, B. van \& QUAGGIO, J.A. Métodos de análise de solo para fins de fertilidade. Campinas, Instituto Agronômico, 1983. 31p. (Boletim 81).

VITTI, G.C. \& MALAVOLTA, E. Fosfogesso - Uso Agrícola. In: MALAVOLTA, E., Coord,, SEMINÁRIO SOBRE CORRETIVOS AGRÍCOLAS. Campinas,SP. Fundação Cargill, p. 161-201, 1985.

WUTKE, A.C.P. \& GARGANTINI, H. Avaliação das possibilidades de escórias de siderurgia como corretivos da acidez do solo. Bragantia, 21(45): 796-805, 1962.
Entregue para publicação em 18.09.91

Aprovado para publicação em 10.04 .92 